\title{
Commentary on Kopiez, Wolf, and Platz: The impact of playing from memory on performance evaluation
}

\author{
BRUNO GINGRAS[1] \\ University of Innsbruck, Innsbruck, Austria
}

\begin{abstract}
Kopiez et al. (this volume) empirically investigated the effect of playing from memory (more specifically, playing with a conspicuously visible music stand) on the evaluation of audiovisual recordings of solo instrumental performances. Their study, a replication of Williamon (1999), corroborates the finding that the presence of a music stand has a small but significant negative effect on performance evaluations. In this commentary, I present some possible explanations for this effect and discuss relevant implications for future research and for professional performers. I also provide some suggestions for improving the experimental design, such as using a better measure of musical sophistication, controlling for the potential visual distractor effect of the music stand, and developing a more comprehensive and statistically robust scale for evaluating performances.
\end{abstract}

Submitted 2017 May 6; accepted 2017 May 12.

KEYWORDS: performance, memory, impression management, musical sophistication

CAN we quantify the impact of playing from memory on listeners' evaluations of a performance? Kopiez et al. (this volume) attempted to do so by using clever audiovisual manipulation techniques to compare the ratings across pairs of performance videos with and without a conspicuously present music stand. The audio tracks were identical in all other ways and were synchronized with the performer's movements. In contrast to an earlier study by Williamon (1999), which the authors sought to replicate, this experimental design ensures that the sound, as well as the temporal association between sound and movements, were exactly the same in both conditions.

\section{THE EFFECT OF PLAYING FROM MEMORY: CAUSES AND CONSEQUENCES}

As noted by the authors, playing from memory is nowadays seen as a sign of virtuosity (Chaffin, Demos, \& Logan, 2016) and maybe even creativity (Czerny, 1991, p. 70), although this practice was not universally endorsed in the $19^{\text {th }}$ century (Bitzan, 2010; Ginsborg, in press) and tends to be associated with specific musical genres (Ginsborg, 2004). Whereas an abundant musicological literature discusses the perceived advantages and disadvantages of playing from memory, there is very little empirical research on the topic, with the exception of Williamon (1999). However, the authors rightly point out that, considering that a number of studies have shown that visual information contributes significantly to the evaluation of a live music performance, the presence of a score or music stand may be expected to affect listeners' impressions.

In my view, we should nevertheless make a distinction between the visual impact of performers' expressive movements and that of a music stand (or score). In the former instance, expressive movements or gestures (Vines, Krumhansl, Wanderley, \& Levitin, 2006; Wöllner, 2008), as well as facial expressions (Thompson, Graham, \& Russo, 2005), have been shown to contribute to the emotional impact of the performance. However, in the case of playing from memory (corresponding visually to the absence of a music stand), we are likely dealing with a second-order, cognitive effect on the evaluation of a performer's virtuosity or (apparent) creativity. In that view, the visible score or music stand may perceptually act as a marker of insecurity, lack of confidence, or lack of virtuosity on the part of the performer, thus negatively affecting the performance's evaluation. In other words, unlike expressive movements, the presence or absence of a stand is not likely to have a direct emotional impact but rather an indirect, cognitive effect. To be sure, playing from memory may allow the performer more freedom with respect to expressive movements, given that he/she is not constrained by the music stand or by looking at the score, thereby possibly indirectly 
enhancing the expressivity of the performance. However, the design used by Kopiez et al. attempted to minimize this potential confound by asking the performer to synchronize his movements to the same playback track for both conditions (playing from memory and playing with a music stand), by making sure that the music stand did not obstruct the listeners' view of the performer (unlike Williamon's study), and by selecting the most persuasive versions in a pre-test.

As pointed out by the authors (Platz \& Kopiez, 2013), the ability to play from memory would thus seem to fall into the category of "impression management", meaning that the presence of a music stand affects the evaluation of a performance through its influence on the performer's perceived competence or "appropriateness" with respect to the audience's expectations, rather than by modulating the perceived expressive qualities of the performance itself. Even though the effect size associated with the presence of a music stand remains relatively modest, this finding, along with earlier results, indicates that future research on music performance evaluation should take into account a broader range of modalities and psychosocial constructs instead of confining itself to a structure-oriented model of musical communication (e.g., Kendall $\&$ Carterette, 1990). For performers, these results also imply that the additional work required to learn to play a piece competently from memory is not done in vain, as it may ultimately lead to more positive evaluations or critical appraisals, especially with respect to performers' perceived understanding and spontaneity (Alessandri, Williamson, Eiholzer, \& Williamon, 2015).

\section{METHODOLOGICAL CONSIDERATIONS}

Turning our attention to the study design, the authors should be praised for including detailed calculations of effect size and a priori statistical power. Furthermore, although replication studies such as this one may lack the glamour associated with more "cutting-edge" research, they are absolutely necessary in a field which has its fair share of issues with reproducibility (Frieler, Müllensiefen, Fischinger, Schlemmer, Jakubowski, \& Lothwesen, 2013; Open Science Collaboration, 2015). In these respects, Kopiez et al. establish a model to follow for all researchers in the field. Nevertheless, the experimental design was perhaps suboptimal in some aspects, and I outline a few suggestions for improvement below.

\section{Musical sophistication}

One possible limitation of the study is that the degree of musical sophistication was only assessed by selfreports on total years of private music lessons and years of daily practice. However, a number of studies have clearly established that the number of years of musical training is not necessarily a good measure of musical sophistication (for a review, see Zentner \& Gingras, in press). The authors could have used a questionnaire specifically designed to assess musical sophistication such as the Goldsmiths Musical Sophistication Index (Gold-MSI, Müllensiefen, Gingras, Musil, \& Stewart, 2014), for which a German version is available (Schaal, Bauer, \& Müllensiefen, 2014). Not only are Gold-MSI scores likely to be a more valid estimation of musical sophistication than years of training, their usage would have allowed the authors to treat musical sophistication as a continuous covariate. This would permit a more sophisticated statistical treatment of the effect of musical sophistication and preclude the need to remove a sizeable number of participants $(N=47)$ who were deemed to be neither experts nor amateurs.

\section{Additional control condition}

Although the effect associated with the presence of a music stand is most probably due to its impact on the performer's perceived competence as discussed in the previous section, this effect could also be plausibly explained by the role of the music stand as a visual distractor. The researchers could have controlled for this effect by including an additional condition featuring a "neutral" object (that is, without any musical connotations) instead of a music stand, for instance a plant, podium stand, or small shelf. This additional condition would have enabled the researchers to partial out the "visual distractor" effect of the music stand from the "impression management" effect. 


\section{Performance evaluation scale}

The authors should be commended for developing and making available their Performance Evaluation Scale (PES). However, the PES would presumably provide more information and achieve a finer discrimination if the authors had used a graded response model (GRM, Samejima, 1969) instead of dichotomizing the items. Moreover, it is not clear that item parameter recovery is adequate for a unidimensional scale with only 4 items. Unfortunately, available literature on this topic is relatively scarce. While De Ayala (1994) showed that, for a unidimensional GRM, parameter recovery was excellent for a 15-item scale with 375 examinees (a sample size which is comparable to the one used in the study by Kopiez et al.), this may not be the case with a 4-item scale. Additionally, in order to arrive at a better understanding of the mechanisms underlying the effect of playing from memory on performance evaluation, the questionnaire should ideally discriminate more clearly between the evaluation of the performer's competence and appropriateness (the "impression management" aspects) and the evaluation of the performance itself (aspects dealing chiefly with emotion and expressivity). Thus, as the authors themselves noted, the PES should probably be treated as an initial step towards the development of a more comprehensive and more statistically robust questionnaire.

\section{NOTES}

[1] Correspondence concerning this commentary should be addressed to: Dr. Bruno Gingras, Institute of Psychology, University of Innsbruck, Innsbruck, Austria, A-6020. Email: brunogingras@gmail.com

\section{REFERENCES}

Alessandri, E., Williamson, V. J., Eiholzer, H., \& Williamon, A. (2015). Beethoven recordings reviewed: a systematic method for mapping the content of music performance criticism. Frontiers in Psychology, 6:57. https://doi.org/10.3389/fpsyg.2015.00057

Bitzan, W. (2010) Auswendig lernen und spielen: Über das Memorieren in der Musik [Learning and playing by heart: Memorizing music]. Frankfurt a.M., Germany: Peter Lang.

Chaffin, R., Demos, A. P., \& Logan, T. (2016). Performing from memory. In S. Hallam, I. Cross, \& M. Thaut (Eds.), The Oxford handbook of music psychology (2nd ed., pp. 559-571). Oxford: Oxford University Press.

Czerny, C. (1991). Von dem Vortrage: Dritter Teil der Vollständigen theoretisch-practischen Pianoforte Schule op. 500 [On performance: Third part of the theoretical-practical piano-forte textbook Op. 500] (Original work published 1839). Wiesbaden, Germany: Breitkopf \& Härtel.

De Ayala R. J. (1994). The influence of multidimensionality on the graded response model. Applied Psychology Measures, 18, 155-170. https://doi.org/10.1177/014662169401800205

Frieler, K., Müllensiefen, D., Fischinger, T., Schlemmer, K., Jakubowski, K., \& Lothwesen, K. (2013). Replication in music psychology. Musicae Scientiae, 17(3), 265-276.

https://doi.org/10.1177/1029864913495404

Ginsborg, J. (2004). Strategies for memorizing music. In A. Williamon (Ed.), Musical excellence:

Strategies and techniques to enhance musical performance (pp. 123-141). Oxford: Oxford University Press.

Ginsborg, J. (2017, in press). Memory in music hearing, listening and performance. In P. Hansen \& B. Blaesing (Eds.), Performing the remembered present: The cognition of memory in dance, theatre, and music. London: Methuen.

Kendall, R. A., \& Carterette, E. C. (1990). The communication of musical expression. Music Perception, 8(2), 129-163. https://doi.org/10.2307/40285493 
Müllensiefen, D., Gingras, B., Musil, J., \& Stewart, L. (2014). The musicality of non-musicians: An index for assessing musical sophistication in the general population. PLoS ONE, 9(2):e89642. https://doi.org/10.1371/journal.pone.0089642

Open Science Collaboration. (2015). Estimating the reproducibility of psychological science. Science, 349(6251. https://doi.org/10.1126/science.aac4716

Platz, F., \& Kopiez, R. (2013). When the first impression counts: Music performers, audience, and the evaluation of stage entrance behavior. Musicae Scientiae, 17(2), 167-197.

https://doi.org/10.1177/1029864913486369

Samejima, F. (1969). Estimation of latent ability using a response pattern of graded scores. Richmond VA: Psychometric Society. https://doi.org/10.1007/BF03372160

Schaal, N. K., Bauer, A. K. R., \& Müllensiefen, D. (2014). Der Gold-MSI: replikation und validierung eines fragebogeninstrumentes zur messung musikalischer erfahrenheit anhand einer deutschen stichprobe. Musicae Scientiae, 18(4), 423-447. https://doi.org/10.1177/1029864914541851

Thompson, W. F., Graham, P., \& Russo, F. A. (2005). Seeing music performance: Visual influences on perception and experience. Semiotica, 156(1/4), 203-227. https://doi.org/10.1515/semi.2005.2005.156.203

Vines, B. W., Krumhansl, C. L., Wanderley, M. M., \& Levitin, D. J. (2006). Cross-modal interactions in the perception of musical performance. Cognition, 101(1), 80-113.

https://doi.org/10.1016/j.cognition.2005.09.003

Williamon, A. (1999). The value of performing from memory. Psychology of Music, 27(1), 84-95. https://doi.org/10.1177/0305735699271008

Wöllner, C. (2008). Which part of the conductor's body conveys most expressive information? A spatial occlusion approach. Musicae Scientiae, 12(2), 249-272. https://doi.org/10.1177/102986490801200204

Zentner, M., \& Gingras, B. (in press). The assessment of musical ability. In J. Rentfrow \& D. J. Levitin (Eds.), Foundations in Music Psychology: Theory and Research. Cambridge, MA: MIT Press. 